\section{Elisabeth Reinhardt}

Universidad de Navarra, Pamplona

Facultad de Teologia

erein@unav.es

DOI: http://dx.doi.org/10.12775/BPTh.2016.023

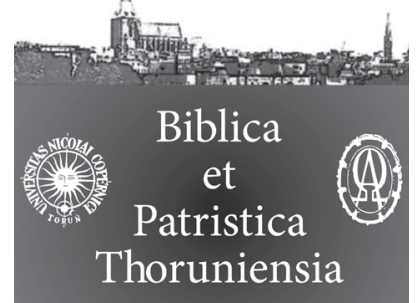

9 (2016) 3: 95-117

ISSN (print) 1689-5150

ISSN (online) 2450-7059

\title{
Vas electionis: el Apóstol Pablo en el comentario de Santo Tomás a la Carta Ad Romanos
}

\section{Vas electionis: The Apostle Paul in the Thomas Aquinas'Commentary on Letter of Saint Paul to the Romans}

\section{Vas electionis. Apostoł Paweł w komentarzu św. Tomasz z Akwinu do Listu do Rzymian}

\begin{abstract}
Resumen. Se estudian varios textos del comentario de santo Tomás de Aquino a la epístola Ad Romanos: primero el prólogo, que contiene una semblanza del Apóstol basada en la metáfora bíblica vas electionis; luego, el comentario a aquellos pasajes donde Pablo habla de sí mismo y de su misión. Los dos tipos de textos del comentario difieren en cuanto al género literario y al modo de exégesis bíblica, pero coinciden en caracterizar al Apóstol: en el prólogo, como el retrato de un santo; en los demás textos, su vida terrena, con las virtudes in fieri que en el prólogo aparecen como perfectamente alcanzadas.
\end{abstract}

\begin{abstract}
The article focuses on various texts of Thomas Aquinas' commentary on the letter of Saint Paul to the Romans: on the one hand, the prologue, which concerns the whole Corpus Paulinum and contains a portrait of the Apostle based on the biblical metaphor vas electionis; on the other hand, the commentary of Aquinas on some parts of Romans where Paul speaks about himself referring to his own life and mission. Both types of texts differ in their literary genre and modes of biblical interpretation, but coincide in presenting the personality of Paul: in the prologue, as the portrait of a saint, whereas the commentary of the selected texts points to Paul's life on earth with his virtues in fieri, which in the prologue are shown as perfectly achieved.
\end{abstract}

Streszczenie. Artykuł skupia się na różnych tekstach z komentarza św. Tomasza z Akwinu do Listu św. Pawła Apostoła do Rzymian: prologu, który dotyczy całego Corpus Paulinum i zawiera portret św. Pawła, opierający się na metaforze vas electionis oraz komentarzu Akwinaty, dotyczącym tych części Listu do Rzymian, w których św. Paweł mówi o sobie samym, odnosząc się do własnego życia i misji. Dwa typy tekstu chociaż różnią się w swoim gatunku literackim, jak i sposobach biblijnej interpretacji, zgadzają 
się w prezentacji osobowości Pawła: w prologu, jako portrecie świętego, natomiast komentarz do wybranych tekstów wskazuje na życie Pawła na ziemi z jego cnotami in fieri, które w prologu są pokazane jako doskonale osiągnięte.

Palabras clave: Tomás de Aquino; Carta a los Romanos; personalidad de san Pablo; exégesis bíblica.

Keywords: Thomas Aquinas; commentary on Romans; personality of Saint Paul; modes of biblical interpretation.

Słowa kluczowe: Tomasz z Akwinu; komentarz do Listu do Rzymian; osobowość św. Pawła; sposoby biblijnej interpretacji.

$\mathrm{D}$ esde mediados del siglo pasado se observa a nivel internacional una renovación de los estudios sobre santo Tomás de Aquino, que conlleva un creciente interés por sus comentarios bíblicos, como denotan las ediciones y traducciones, así como los estudios de metodología y contenido ${ }^{1}$. Junto a los comentarios, se está investigando en la apoyatura bíblica de toda su teología, tanto en el planteamiento mismo como en el desarrollo. Este enfoque bíblico de la ciencia teológica aparece ya en las intervenciones durante su examen de acceso al título de Magister in Sacra Pagina (Universidad de París, 1256); estos textos de su inceptio, que tienen carácter programático, han sido identificados hace relativamente poco tiempo y están siendo objeto de estudio científico ${ }^{2}$.

Como es sabido, una parte considerable de la obra teológica del Aquinate es la enseñanza dedicada directamente a la Biblia. A lo largo de su vida comentó varios libros del Antiguo Testamento ${ }^{3}$. En cuanto al Nuevo Testamento, aportó un trabajo bíblico de notable envergadura. En él ocupa un lugar especial la Glossa continua in Matthaeum, Marcum, Lucam, Ioannem, que consiste en aportar para cada versículo del Evangelio las explicaciones más relevantes de

1 Se refleja, por ejemplo, en: J.-P. Torrell, Nouvelles recherches thomasiennes; y recientemente, en la obra colectiva: Vijgen, J., Roszak, P. (eds.), Reading Sacred Scripture.

2 Después de las aportaciones de Weisheipl, Torrell, Elders, Lobato y otros, se ha publicado una monografía, en continuación con los estudios anteriores, que demuestra la autenticidad tomasiana de los textos de la inceptio y concluye que contienen las líneas maestras de todo el trabajo teológico del Aquinate: vid. M. Estler, «Rigans montes» (Ps 104,13).

3 En la época de Colonia, siendo discípulo de san Alberto Magno, dio clases leyendo cursorie Jeremías; Lamentaciones y una parte de Isaías; de la época de madurez, cuando era lector del convento de santo Domingo en Orvieto (1261-1265), procede su Expositio in Iob ad litteram; y al final de su vida, en Nápoles, comentó los Salmos (Postilla super Psalmos) hasta Sal 54 [55], un texto que existe en forma de reportatio. 
los Padres; se conoce también como Catena aurea in quatuor evangelia, a partir de los siglos XV-XVI, por la fama que había adquirido ${ }^{4}$. En su docencia comentó los evangelios de san Mateo y san Juan ${ }^{5}$, y las catorce epístolas del Corpus Paulinum ${ }^{6}$. En las obras teológicas de carácter especulativo son frecuentes las citas del Apóstol, a veces como referencias para ilustrar una idea, pero generalmente forman parte del hilo argumental, como objeción para precisar un aspecto o como base para una conclusión. Este modo de proceder se puede observar tanto en la Summa Theologiae como en las Cuestiones disputadas.

Aunque el frecuente uso de los textos paulinos, además de los comentarios, permite concluir el aprecio del Aquinate por san Pablo, cabe preguntar qué pensaba de él personalmente. Donde más se extiende acerca de la persona del Apóstol y muestra una particular sintonía con él es en sus comentarios a las epístolas paulinas. Todos ellos llevan un prólogo que comienza con una frase de la Sagrada Escritura, relacionada con el contenido específico de cada epístola. A esa frase temática sigue luego un texto breve que contextualiza la Carta e introduce brevemente su contenido ${ }^{7}$.

Entre estos prólogos destaca el que antecede al comentario Ad Romanos, porque tiene un carácter general. Comienza con una semblanza de san Pablo que a pesar de su brevedad constituye el tratamiento más extenso y profundo de su persona en las obras de santo Tomás. Además de caracterizar a la persona del Apóstol, el prólogo ofrece también un esquema general de todas sus epístolas. Por encima de las diferencias de tiempo, lugar, destinatarios y motivo de las Cartas, el Aquinate discierne en ellas una profunda unidad de contenido teológico, ya que entiende que todas ellas versan sobre la gracia de Cristo, con-

4 Sobre el origen del apelativo aurea, cfr. J. A. Weisheipl, Tomás de Aquino, pp. 208 -209; para más detalles, vid. J.-P. Torrell, Amico della verità, pp. 192-198.

5 De su docencia en Paris proceden la Lectura super Matthaeum y la Lectura super Ioannem; se trata en ambos casos de una reportatio de las clases, pero la del evangelio de san Juan fue corregida por Tomás.

6 Excepto una parte, de 1 Co 7, 10 hasta el final del capítulo 10, donde falta el texto de santo Tomás y fue sustituido posteriormente por un texto de Pedro de Tarantasia (†1276), en una redacción atribuida a Nicolás de Gorrán (†ca. 1295). Cfr. J.-P. Torrell, Amico della verità, pp. 341-342.

7 En el siglo XIII, los prólogos que anteponían los teólogos a sus comentarios bíblicos solían seguir un esquema de tres partes: una frase bíblica, llamada "tema", luego la copia del prólogo del Seudo-Jerónimo con los datos contextuales del libro sagrado, y unas observaciones que añadía el propio autor del comentario. Este esquema lo sigue santo Tomás en sus comentarios a Isaías, Jeremías, los Salmos y al Evangelio de san Juan, pero en el prólogo que se refiere al Corpus Paulinum no se atiene a estas pautas. Cfr. Th. Domanyi, Der Römerbriefkommentar des Thomas von Aquin, p. 188. 
siderada desde distintos puntos de vista: en la epístola a los hebreos, es la gracia de Cristo como Cabeza de la Iglesia; en las denominadas epístolas pastorales se considera en relación con los miembros principales; y finalmente la gracia en cuanto a su distribución a los pueblos llamados a formar parte del Cuerpo Místico. Este prólogo alude también a otras cuestiones generales de las epístolas, de modo que se puede considerar realmente como el pórtico de sus comentarios al Corpus Paulinum; en efecto, el comentario de cada una de las demás Cartas tiene su propio prólogo que se abre con una frase bíblica de carácter temático acerca del contenido.

\section{Vas electionis. Una semblanza de san Pablo en el prólogo}

Este prólogo general se introduce con la cita de Hch 9,15: Vas electionis est mihi iste. El Aquinate escoge una metáfora bíblica para caracterizar a la persona del Apóstol y su obra evangelizadora que se refleja en las distintas Cartas. ¿Por qué una metáfora y concretamente ésta? Al final de este estudio será posible retomar la pregunta para examinar los niveles de interpretación bíblica en los que se mueve santo Tomás y el alcance significativo de las imágenes que emplea.

En primer lugar cabe señalar que la expresión vas electionis une el Antiguo y el Nuevo Testamento. Recoge la imagen bíblica de Dios como alfarero que produce las vasijas que quiere y con la forma que quiere, y hace referencia a los usos variados a los que se destinan ${ }^{8}$. La metáfora del "vaso escogido" constituye un puente entre ambos Testamentos, no solo por las palabras mismas sino por la intención del autor de la Sagrada Escritura a la que el autor del comentario acude como fuente principal de la verdad. Las distintas citas bíblicas que aporta santo Tomás ilustran la libertad y soberanía del Creador, que dota a cada persona conforme al destino que le da. Esta imagen de vas electionis adquiere particular fuerza en Hch 9,15, porque es Jesucristo quien la usa cuando encarga a Ananías que reciba a Saulo, ya convertido, en la comunidad cristiana. Este encargo introduce cierto dramatismo en el relato, ya que el discípulo expone

8 En cuanto al Antiguo Testamento, santo Tomás hace referencia a Jr 18,1-6; Is 45,9; Ps 99 (Vg), 3 para expresar que el artífice hace el recipiente como él quiere; que el recipiente está sometido a quien lo hace y que no puede pedir cuentas a su hacedor. En cuanto al Nuevo Testamento, continuando con la imagen del recipiente, remite a $\mathrm{Rm} \mathrm{9,20} \mathrm{que} \mathrm{expresa}$ también la idea de que el recipiente no puede protestar de cómo ha sido hecho, y añade la referencia a $2 \mathrm{Tm}$ 2,20 sobre la variedad y calidad de recipientes que hay en una casa según los usos que tienen. La palabra hebrea empleada con más frecuencia en el Antiguo Testamento

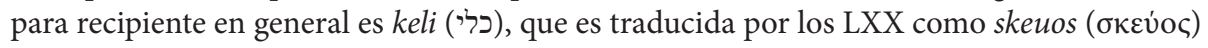
y se usa igual en el Nuevo Testamento, con la traducción latina de vas. 
su temor, porque tiene noticia de la actividad persecutoria de Saulo que causa gran sufrimiento a los cristianos. Ahora bien, las palabras de Cristo sobre la elección y misión de Saulo también se refieren al sufrimiento, pero ahora al que sobrevendrá a Saulo: "Yo le mostraré lo que deberá sufrir a causa de mi nombre" (Hch 9,16) ${ }^{9}$. A la vista de este contexto adquiere particular relieve el hecho de que el Aquinate haya elegido la frase Vas electionis est mihi iste para caracterizar al Apóstol y comentar su enseñanza. Se refuerza el significado de estas palabras, porque las dice Jesucristo, aplicando esta imagen bíblica a una persona que hasta ese momento le había perseguido y que se acaba de convertir para luego llevar su "Nombre" a todas partes.

La breve frase que preside el texto del prólogo se despliega a continuación en nuevas imágenes bíblicas que el Aquinate descubre como virtualmente contenidas en ella por medio de un análisis conceptual: un recipiente cualquiera tiene cuatro características, a saber la hechura, el contenido, el uso y el provecho. A continuación desarrolla estos aspectos con un lenguaje lleno de imágenes y nuevas referencias bíblicas, para mostrar en qué sentido Pablo era una persona extraordinaria, un "vaso de elección".

\section{a) El material y la hechura (constitutio)}

La imagen que emplea el Aquinate para expresar en términos generales el valor de Pablo como "vaso de elección" es la que aplica el libro del Sirácida al sumo sacerdote Simón: "como vaso de oro macizo, adornado con toda clase de piedras preciosas" (Si 50,10). Luego justifica esta comparación, detallando distintos aspectos. Pablo fue un recipiente de oro finísimo por el fulgor de su sabiduría ${ }^{10}$, de la que da testimonio el apóstol Pedro ${ }^{11}$. Fue un vaso sólido por la virtud de la caridad ${ }^{12} \mathrm{y}$ adornado con piedras preciosas, que son sus virtudes ${ }^{13}$. Tal dignidad del recipiente, añade santo Tomás, corresponde a lo que se obten-

9 Para las citas de la Sagrada Escritura en español se utiliza la siguiente edición: Sagrada Biblia, Facultad de Teología, Universidad de Navarra, Eunsa, Pamplona, 5 vols., 1997-2004 .

10 Según Gn 2,12 y Pr 3,15.

11 Santo Tomás cita literalmente 2 P 3, 15, en el contexto de mantener una conducta intachable de cara la segunda venida del Señor: "Así os lo escribió también nuestro querido hermano Pablo según la sabiduría que se le otorgó".

12 Según Ct 8,6 que compara la fuerza del amor con la de la muerte y $\mathrm{Rm} \mathrm{8,38-39}$ donde afirma Pablo mismo que ninguna fuerza de este mundo puede separarle de su amor a Cristo.

13 Las citas bíblicas que respaldan esta afirmación son de textos paulinos: 1 Co 3,12 y 2 Co 1,12 . 
drá de él, a saber la enseñanza de los misterios divinos, así como la instrucción en la caridad y en otras virtudes ${ }^{14}$.

\section{b) El contenido (repletio)}

Lo propio de los vasos es que se les llene con líquidos variados, según su hechura y capacidad, así las personas son también diferentes entre sí y pueden ser "llenadas" por Dios con dones espirituales variados, según 1 Co 12,8. En cuanto a Pablo, continúa santo Tomás, estuvo completamente lleno de un líquido precioso, a saber "el nombre de Cristo"15, que ocupaba por entero la vida del Apóstol. El nombre de Cristo estaba en su mente y era su único interés, como dice en 1 Co 2,2; llenaba también su querer y sus afectos, según afirma en Rm 8,35 , y toda su vida de relación, hasta la identificación total con Cristo, como él mismo lo expresa en Ga 2,20. Se observa que las citas bíblicas con las que el Aquinate ilustra este rasgo definitorio son frases que dice san Pablo de sí mismo y que conectan directamente con su propia vivencia.

\section{c) El uso (usus)}

Con referencia a los distintos usos que se da a los recipientes ( $\mathrm{Rm} 9,21)$, Pablo fue destinado a un uso nobilísimo, que era llevar el nombre de Cristo lejos, a los que se hallaban a gran distancia de Él por el pecado y la oscuridad de la mente. Aquí habla santo Tomás, con más referencias bíblicas, del plan divino de salvación y su transmisión "hasta nosotros", primero en el Antiguo Testamento, luego en el Nuevo, y después en la propagación del Evangelio por medio de los Apóstoles.

A continuación profundiza, mediante otros textos de la Sagrada Escritura, en el modo en que san Pablo llevó el nombre de Cristo en su tarea de evangelizar, y señala tres características. En primer lugar, portaba el nombre de Jesús en su propio cuerpo al imitarle en su vida y su pasión; esto último incluso con

14 Las referencias bíblicas aquí son 1 Co 2,6 y el capítulo 13, y Col 3,12 donde se destaca la misericordia.

15 El texto del prólogo remite para las palabras "oleum effusum nomen tuum" a Ct 1,2, pero en realidad es Ct 1,3; como santo Tomás solo indicaba los capítulos, se trata de un fallo de los editores que se corregirá en la edición crítica, ya en marcha. En cuanto a Ap 3,12: "Scribam super eum nomen meum", que refiere a continuación, no es literal de la Vulgata, sino que contrae la frase del texto bíblico, que dice: "Scribam super eum nomen Dei mei, et nomen civitatis Dei mei novae Jerusalem, quae descendit de caelo a Deo meo, et nomen meum novum". 
señales visibles, como afirma en Ga 6,17. En segundo lugar, llevaba el nombre de Cristo en la boca por la grandísima frecuencia con que hablaba de Él en sus epístolas, haciéndose realidad las palabras del Señor en Mt 12,24: "De la abundancia del corazón habla la boca”. Santo Tomás amplía esta idea mediante la exégesis alegórica, poco frecuente en él. Compara a san Pablo -que llevaba el nombre de Cristo en la boca- con la paloma que llevó una rama verde de olivo al arca de Noé (Gn 8,11), como signo de la misericordia divina; así, el Apóstol llevó el nombre de Jesús Salvador -como una rama verde llena de vigor-al Arca que es la Iglesia ${ }^{16}$, mostrando de muchas maneras la gracia y la misericordia de Cristo. En la misma línea de interpretación, usando ahora la tipología, compara a Pablo con David, porque en ambos mostró Dios su misericordia y su perdón, de modo que esos libros bíblicos son un estímulo para nuestra esperanza, más aún al considerar que los Salmos de David y las epístolas de san Pablo son libros muy leídos del Antiguo y del Nuevo Testamento, respectivamente ${ }^{17}$, y que en ambos Testamentos está contenida prácticamente toda la doctrina teológica. Finalmente, en tercer lugar, la misión de Pablo de dar a conocer a Cristo ha tenido un alcance universal, porque llegó no solo a sus oyentes inmediatos, sino también a los ausentes y a las futuras generaciones.

El Aquinate ve necesario añadir algo más, y es el modo excelente en que Pablo llevó el nombre de Dios a todas partes: en primer lugar, por la gracia de la elección divina de la que fue objeto, según Ef 1,4; luego, por la fidelidad en su respuesta sin pensar en sí mismo y por la generosidad extraordinaria en el cumplimiento de su tarea; además, porque lo hizo de un modo singularmente excelente. Al mencionar cada uno de estos aspectos repite las palabras vas electionis, como reafirmando esa singularidad.

\section{d) En cuanto al provecho (fructus)}

Por último, en cuanto al provecho que se obtiene de una vasija, Pablo fue sumamente útil por su integridad moral y la ausencia de error en la doctrina, conforme a lo que se dice en $2 \mathrm{Tm}$ 2,21. La utilidad se muestra en que se cumplieron las palabras del Señor a Ananías en Hch 9,15, porque efectivamente llegó a ser el Apóstol de los gentiles; llevó el nombre de Cristo "ante los reyes" -el rey

16 La imagen del arca de Noé para significar la Iglesia aparece muy pocas veces en las obras de santo Tomás (por ejemplo en STh III, q. 73 a. 3c; Super I Thes., proem., y siempre con referencia a 1 P 3,20 donde se relaciona el arca con el bautismo como medio de salvación.

17 Es evidente que Tomás habla desde el contexto de su tiempo, en el cual todos los Salmos eran atribuidos a David y todas las Cartas del Corpus Paulinum a Pablo. 
Herodes Agripa y el emperador Nerón- y lo mostró también ante los "hijos de Israel", con los que disputaba sobre la fe en Cristo, como se narra en Hch 9,22.

Santo Tomás desarrolla hasta este momento la noción bíblica de vas electionis. Se puede considerar ahora la división conceptual que hace para ello, que proviene en parte de Aristóteles y en parte de san Agustín. En efecto, como observa Domanyi, los términos constitutio y repletio son de procedencia aristotélica, mientras usus y fructus recuerdan las expresiones de uti y frui que son de origen agustiniano ${ }^{18}$. Cabe mencionar que estas dos nociones $-u t i$ y frui- articulan las Sentencias de Pedro Lombardo que el Aquinate ya había comentado antes de dedicarse a la enseñanza del Corpus Paulinum.

Al final de su elogio de la persona de san Pablo y antes de comentar la Carta se observa un paso metodológico en continuidad con todo lo anterior (ex praemissis verbis), mediante el esquema aristotélico de las cuatro causas. La causa eficiente es el autor mismo de las epístolas; el contenido, a saber el nombre y la doctrina de Cristo, es la causa material; el modo de "llevar" el contenido -en forma de cartas- es la causa formal; y el fruto o resultado es la causa final. Este paso se puede considerar como una herramienta metodológica, con otros recursos de método y lenguaje, para mostrar la coherencia interna y la exactitud de lo dicho anteriormente y conducir a la segunda parte del prólogo, mucho más breve, que expone la estructura interna de las epístolas bajo el punto de vista de la gracia, así como algunos aspectos históricos o que considera en discusión acerca de la Carta a los Romanos.

\section{Rasgos de la personalidad de san Pablo en el comentario}

A lo largo del comentario Ad Romanos aparecen algunas referencias más sobre la persona de Pablo, que de algún modo complementan la imagen que ofrece el prólogo; se trata de pasajes en los cuales el Apóstol habla de sí mismo al comunicarse con los destinatarios de la Carta. Aunque el Aquinate se limita a comentar el texto de modo objetivo, se trasluce una cercanía personal a san Pablo, de estilo diferente a la que muestra el prólogo. Vamos a considerar sucesivamente estos lugares, para sacar después algunas conclusiones.

\section{a) La autopresentación de san Pablo}

$\mathrm{Al}$ entrar en el comentario del texto nos encontramos con las palabras con que el autor de la Carta se presenta ante los destinatarios: "Pablo, siervo de Jesucris-

18 Cfr. Th. Domanyi, Der Römerbriefkommentar des Thomas von Aquin, p. 189. 
to, apóstol por vocación, designado para el Evangelio de Dios (Rm 1,1)"19. Es la autocomprensión de san Pablo, su identidad, con la que quiere ser conocido por los receptores de la Carta. Es una frase muy breve, en la que el Aquinate lee mucho más de lo que dicen literalmente las palabras y que comenta de forma detallada ${ }^{20}$. Lo hace desarrollando los cuatro aspectos expresados en la frase: el nombre de la persona, su condición, su dignidad y su encargo.

\section{Nombre}

El Aquinate observa que el nombre Paulus no parece hebreo ${ }^{21}$, pero lo admite como hipótesis al considerar el significado de la palabra en varios idiomas ( $\mathrm{n}$. 17): el equivalente en hebreo -dice- es "maravilloso o escogido"; en griego significa "quieto" o "en reposo"; en latín, "pequeño". Estima que todas estas acepciones convienen a Pablo y lo ilustra con referencias bíblicas: elegido en cuanto a la gracia (vas electionis, según Hch 9,15) y admirable en sus obras (Vas admirabile opus Excelsi, según Si 43,2); vivió "en quietud" por la contemplación, según $\mathrm{Sb} 8,16$; y fue pequeño por la humildad, porque se veía a sí mismo como "el menor de los apóstoles" (1 Co 15,9) 22 . A estos datos añade el Aquinate una breve indagación histórica sobre el momento en que el nombre Saulus, como aparece en los Hechos de los Apóstoles, pudo ser cambiado en Paulus (n. 18).

\section{Condición}

Pablo se presenta en la condición en la que él mismo se ve: servus Iesu Christi, que el Aquinate decide explicar en forma dialéctica, en tres pasos: videtur quod, sed contra, dicendum quod, argumentando cada paso con citas de la Sagrada

19 El texto que comenta santo Tomás dice: "Paulus servus Iesu Christi, vocatus apostolus, segregatus in Evangelium Dei."

20 Super Epistolam ad Romanos, lect. 1, nn. 15-24 de la edición Marietti. Las referencias de números con respecto al texto latino del comentario corresponden a esta edición.

21 En la lengua hebrea, la letra פ tiene doble pronunciación: el sonido original es “f”, pero en determinados casos se pronuncia como "p", que la vocalización masorética señala con un punto en el centro. Es posible que el Aquinate conociera esta característica de la lengua hebrea, porque comenta: "Si tamen aliquod elementum ei [a la letra "p"] propinquum sumatur id quo est $P$ potest esse hebraeum." (n. 16)

22 Santo Tomás dice literalmente (Ad Romanos, n. 17): "Electus quidem fuit quantum ad gratiam, unde Act. IX, v. 15: Vas electionis est mihi iste. Mirabilis fuit in opere, Eccli. XLIII, 2: Vas admirabile opus Excelsi. Quietus in contemplatione, Sap. c. vII, 16: Intrans in domum meam conquiescam cum illa. Modicus per humilitatem, I Cor. $\mathrm{x}$, 9: Ego autem sum minimus apostolorum." 
Escritura (nn. 20-21). Vale la pena seguir todos los pasos, para averiguar por qué procede así. Parece, según Gn 9,25, que la condición de siervo es en sí misma abyecta, pero se vuelve positiva al añadir "de Jesucristo", que quiere decir Salvador y Ungido en su dignidad como Sacerdote, Rey y Profeta. En efecto, es loable someterse a un bien superior como la salvación y la unción espiritual de la gracia, porque tanto más perfecta es una cosa cuanto más se someta a lo que constituye su perfección, como el cuerpo al alma y el aire a la luz, según Sal 115,16 (Vg): "soy tu siervo, o Dios"23. De ahí que no hay contradicción entre dignidad y sometimiento. Sin embargo, argumenta el Aquinate, está escrito en Jn 15,15 que el Señor no quiere a sus apóstoles como siervos sino como amigos. Pero resuelve esta aparente contradicción distinguiendo dos tipos de "esclavitud": la del puro temor, que no conviene a los santos, según $\mathrm{Rm} \mathrm{8,15;} \mathrm{y} \mathrm{la} \mathrm{de} \mathrm{la}$ humildad y el amor, sabiéndonos "siervos inútiles" (Lc 17,10), que es propia de los santos. Podría terminar aquí el argumento, pero santo Tomás profundiza más en el tema, uniendo libertad, servicio, amor y amistad. Mientras que la persona libre es dueña de sus propios actos (causa sui), el esclavo está obligado a actuar por imposición de otro (causa alterius), que es el sometimiento por temor. En cambio, en una relación de amistad se da un sometimiento por amor para hacer el bien y servir al amigo "por él mismo" (propter ipsum), como dice Aristóteles. ${ }^{24}$ Se puede observar que el método dialéctico, en este caso, tiene la función de discernimiento y profundización doctrinal.

\section{Dignidad}

A continuación, san Pablo se presenta a sí mismo como vocatus apostolus. Santo Tomás (n. 22) destaca en primer lugar la dignidad de los apóstoles en la Iglesia en cuanto "enviados" con la autoridad de Cristo para continuar su propia misión (Jn 20,21). El término vocatus lo entiende en un triple sentido: que Pablo se sabe apóstol por gracia divina, porque nadie puede serlo por iniciativa humana; que es apóstol como por antonomasia, porque ha trabajado más que ningún otro; y señala la humildad de Pablo, que se siente indigno y no osa llamarse a sí mismo apóstol, sino que otros lo llaman así.

23 La cita de santo Tomás es: “O Domine, quia ego servus tuus sum”. El texto completo de Sal 115, 16 (Vg) es: "o Domine quia ego servus tuus, ego servus tuus et filius ancillae tuae disripuisti [sic] vincula mea."

24 Santo Tomás indica el libro IX de la Ética, cap. 4. 


\section{Vocación y misión}

Finalmente, continúa santo Tomás, se presenta Pablo por su ministerio (n. 23): segregatus in evangelium Dei, escogido con la finalidad precisa de convertir a los gentiles; el Aquinate relaciona esta expresión con Ga 1,15 donde dice Pablo que fue "escogido (segregatus) desde el seno de su madre" 25 , o bien "escogido" o separado de los otros discípulos, según Hch 13,2: "Separadme a Saulo y Bernabé" para llevar el Evangelio a los gentiles.

Se detiene a considerar la expresión in Evangelium Dei, que es la "buena noticia”, porque anuncia la unión del hombre con Dios que es su verdadero bien, según Sal 72, 28 (Vg). Esta unión se realiza en tres dimensiones: en Cristo mismo por la unión hipostática (per gratiam unionis), en nosotros por la filiación divina en esta vida mediante la gracia (per gratiam adoptionis) y por la plenitud de esta filiación en la bienaventuranza eterna (per gloriam fruitionis). Cada uno de estos pasos se apoya en una referencia bíblica, y la conclusión consiste en una cita del profeta Isaías (Is 21,10) para mostrar que este anuncio -el Evangelio- no es invención humana sino obra de Dios ${ }^{26}$. Gilles Berceville, en el prefacio a la traducción francesa del comentario, llama la atención sobre este breve texto, donde el Aquinate ofrece una noción lo más amplia posible de la palabra "evangelio", que incluye a la vez la base y las líneas maestras de lo que entiende por la sacra doctrina ${ }^{27}$.

En los versículos 2 a 4, el texto paulino amplía la expresión "Evangelio de Dios" con una síntesis del anuncio evangélico acerca de Jesucristo (Rm 1,2-4). En su comentario, santo Tomás alude primero al origen del Evangelio en cuanto revelación divina (nn. 26-27) para referirse después al contenido, que es el Hijo de Dios, con un breve desarrollo cristológico: el origen de Jesucristo, su

25 El Aquinate añade, en una interpretación alegórica, que por "el seno de mi madre" $(\mathrm{Ga} 1,15)$ se puede entender la Sinagoga o el judaísmo; esta interpretación figura también en su comentario Ad Galatas, n. 41.

26 Cfr. Ad Rom, nn. 23-24. Se reproduce a continuación todo el texto, por la perfecta síntesis teológica y bíblica que ofrece: "Evangelium autem idem est quod bona annuntiatio. Annuntiatur enim in ipso coniunctio hominis ad Deum, quae est bonum hominis, secundum illud Ps. LXxiI, 28: Mihi autem Deo adhaerere bonum est. - Triplex autem coniunctio hominis ad Deum annuntiatur in evangelio. Prima quidem per gratiam unionis, secundum illud Io. I, 14: Verbum caro factum est. - Secunda per gratiam adoptionis, prout inducitur in Ps. LXxxi, 6: Ego dixi: Dii estis et filii Excelsi omnes. - Tertia per gloriam fruitionis, Io. XVII, 3: Haec est vita aeterna. Is. LII, 7: Quam pulchri super montes pedes annuntiantis. Haec autem annuntiatio non humanitus sed a Deo facta est, Is. XxI, 10: Quae audivi a Domino exercituum, Deo Israel, annuntiavi vobis. Unde dicit in Evangelium Dei.

27 Cfr. G. Berceville, Avant-propos, pp. 7-17. 
potestad y su liberalidad al conferir sus dones (nn. 28-59). Observa que san Pablo se ve a sí mismo como uno de los apóstoles que ha recibido la gracia y la misión de llevar el Evangelio a todos los pueblos, y se dirige particularmente a los fieles que están en Roma (Rm 1,5-7). El Aquinate lo considera una manifestación de la liberalidad de Dios, que da a todos los fieles el don de la gracia y a algunos, el don y oficio espiritual (munus spirituale) de ser apóstoles, "que es el más alto entre los grados eclesiásticos"28. A continuación describe las características de este apostolado ministerial: primero su fin, que es lograr la obediencia de la fe en quienes reciben el mensaje (n. 62); luego la amplitud en cuanto se dirige a todos los gentiles, sin excluir a los judíos, que con frecuencia vivían entre los gentiles (n. 63); además lo hacía pro nomine Christi, es decir con la autoridad recibida de Cristo y para difundir el nombre de Cristo, como es propio de Pablo en cuanto vas electionis (n. 64), como ya había expuesto en el prólogo; finalmente, la potestad apostólica que Pablo tenía sobre los destinatarios de la Carta (n. 65).

A continuación comenta que los destinatarios son los fieles de Roma, a quienes Pablo considera como amados y llamados por Dios: en su interior son llamados directamente por Dios para ser santos, y exteriormente por medio de otras personas (nn. 67-69). Los bienes que les desea Pablo son la gracia y la paz de Dios Padre por medio de Jesucristo (nn. 70-73). El primero de los bienes, dice, es la gracia que nos justifica; luego la paz, que recibirá su última y definitiva perfección en el cielo cuando la voluntad descanse en la plenitud de todo bien ${ }^{29}$. Aquí termina la parte de saludos a los fieles que están en Roma.

Después de los saludos, observa santo Tomás, comienza propiamente la epístola. En estas frases iniciales, redactadas también en primera persona ( $\mathrm{Rm}$ 1,8-16), el Apóstol expresa su afecto a los cristianos que están en Roma ${ }^{30}$, y lo hace de tres modos: mediante la acción de gracias, la oración y el deseo de visitarlos. La acción de gracias, dice el Aquinate, debe preceder siempre a nuestras peticiones, porque necesitamos de la bondad de Dios para todo lo que

28 Se refiere santo Tomás al sacramento del Orden en sus tres grados, en este caso el episcopado; en cambio cuando nombra la "gracia común a todos los fieles", alude al bautismo.

29 "Deinde ponuntur bona quae eis optat, quae sunt gratia et pax. Quorum unum, scilicet gratia, est primum inter Dei bona, quia per eam iustificatur impius, infra 3,24: Iustificati gratis per gratiam ipsius. - Alius autem, scilicet pax, est ultimum quod in beatitudine perficitur. Ps 14,14: Qui posuit fines tuos pacem. Tunc enim erit perfecta pax, quando voluntas requiescet in plenitudine omnis boni, consequens immunitatem ab omni malo. Is. 32,18 : Sedebit populus meus in plenitudine pacis."

30 "Primo ostendit affectum suum ad eos quibus scribebat ut reddat auditores benevolos” (n. 74). 
hacemos, de modo que -igual que el ciclo del agua en la naturaleza- nuestras acciones de gracias revierten luego en nuevos beneficios. Comenta que Pablo da gracias a Dios creador y providente, por medio de Jesucristo, por todos ellos, en concreto por su fe que desde Roma se extiende a todas partes (nn. 75-77). Le parece acertado y una muestra especial de afecto que el apóstol, al asegurarles su oración por ellos, tome a Dios por testigo, porque solo Dios conoce el secreto del corazón humano donde nace la oración; observa además que Pablo se refiere a una relación personal suya con Dios cuando dice: "a quien sirvo con todo mi espíritu en la predicación del Evangelio de su Hijo" (Rm 1,9).

Las oraciones incesantes de san Pablo contienen una petición intensa, como muestra de su afecto: "que, si es voluntad de Dios, algún día tenga ocasión favorable de ir donde vosotros" (Rm 1,10). Este deseo, comenta santo Tomás, hace que sea una oración intensa, llena de deseo, perseverante y recta (n. 86), y la causa del deseo es que su visita les ayude espiritualmente y les fortalezca, además de experimentar el mutuo consuelo por poseer la misma fe (nn. 87-88). Sin embargo no son meros deseos de Pablo, comenta el Aquinate, sino que hay también un propósito efectivo y constante por encima de los impedimentos que frustraron sus planes en otras ocasiones (nn. 90-91). El motivo para seguir intentándolo es doble: obtener algún fruto de su predicación y el compromiso de evangelizar, porque se sabe "deudor de griegos y de bárbaros, de sabios y de ignorantes" (Rm 1,13). Por eso, comenta santo Tomás, el Apóstol siente la urgencia de evangelizar en Roma (nn. 92-94) y excluye cualquier impedimento subjetivo cuando dice a los romanos: "No me avergüenzo del Evangelio" (Rm $1,16 a)$ y a los corintios (1 Co 1,23) que predica a Cristo crucificado, "escándalo para los judíos, necedad para los gentiles; pero para los llamados, judíos y griegos, [...] fuerza de Dios y sabiduría de Dios" (n. 96).

\section{b) Otros lugares en que san Pablo habla en primera persona}

A lo largo de la epístola hay algunos pasajes más en que san Pablo hace referencias a sí mismo, de modo que en esos casos el texto remite más directamente al autor de la Carta y crea una mayor proximidad. Nos centramos en aquellos lugares en los cuales el comentario de santo Tomás expresa algo sobre la personalidad y la misión del Apóstol ${ }^{31}$.

31 Omitimos el comentario a Rm 7,7-24 sobre la relación entre ley y pecado; aunque san Pablo habla en primera persona, lo hace dentro de un desarrollo doctrinal de una experiencia común y porque aquí el comentario del Aquinate no personaliza. 
San Pablo, judío y apóstol de los gentiles

En los capítulos 9 a 11, san Pablo habla de sí mismo como miembro del pueblo elegido y Apóstol de Cristo tras su conversión. No nos referiremos a todo este texto, que merecería un tratamiento aparte ${ }^{32}$, sino que seleccionamos dos lugares más significativos.

Rm 9,1-5: "Os digo la verdad en Cristo, no miento, y mi conciencia me lo atestigua en el Espíritu Santo: siento una pena muy grande y un continuo dolor en mi corazón. Pues le pediría a Dios ser yo mismo anatema de Cristo a favor de mis hermanos, los que son de mi mismo linaje según la carne. Ésos son los israelitas: a ellos pertenece la adopción de hijos y la gloria y la alianza y la legislación y el culto y las promesas; de ellos son los patriarcas y de ellos según la carne desciende Cristo, el cual es sobre todas las cosas Dios bendito por los siglos. Amén." A estas palabras dedica santo Tomás la lección primera del comentario al capítulo 9. Hace considerar la fuerza con que se expresa Pablo: primero como simple afirmación de que dice la pura verdad como corresponde a todo predicador, luego invocando el infalible testimonio de Dios en Jesucristo; después apela a su propia conciencia, "testigo infalible de los santos", e invoca al Espíritu Santo para la ausencia de error (n. 736). A continuación habla de la tristeza y el dolor de Pablo por la "caída" de su pueblo: un dolor grande y loable, porque proviene del amor de Dios, según 2 Co 7,10; se trata de una tristeza continua o habitual, según Jr 9,1, y es real porque procede del corazón, según Lm 1,22. Para expresar su dolor con un signo, dice santo Tomás, el Apóstol estaría dispuesto a ser "anatema" por amor a ellos, en el sentido de ser apartado de Cristo, para quien es todo su amor (n. 741). Al hablar el Apóstol de "los israelitas", el Aquinate lo entiende como expresión de la dignidad del pueblo elegido y detalla a continuación en qué consiste esa dignidad: la descendencia de Jacob-Israel; los beneficios que Dios les otorgó: en primer lugar al adoptar a su pueblo como "primogénito" (Ex 4,22) con vistas a la gloria futura de los hijos de Dios; la dignidad en cuanto descendientes de los patriarcas, "amados por Dios"; finalmente, la dignidad de su prole, porque de ese pueblo nació Cristo, según la carne. En la doxología que concluye las palabras de san Pablo ve santo Tomás una confesión cristológica que excluye todas las herejías (nn. 742-727).

32 Sobre este tema es de interés un estudio reciente: Taylor Coolman, H., Romans 9-11, pp. 101-112. La autora se hace eco de la discusión, que todavía existe, acerca de la opinión de santo Tomás sobre el pueblo judío y que se debe quizá a una lectura parcial de sus escritos. Recomienda en concreto leer el comentario del Aquinate Ad Romanos, capítulos 9-11, para acertar en esta cuestión. 
Rm 11,13-14: "Pero a vosotros, los gentiles, os digo: siendo yo, en efecto, apóstol de las gentes, hago honor a mi ministerio, por si de alguna forma provoco celo a los de mi raza y salvo a algunos de ellos." En su comentario, el Aquinate destaca que san Pablo no deja de sentirse judío, que ama a su pueblo, les perdona su rechazo de Cristo y aguarda con esperanza su conversión. Observa que hasta ese momento el Apóstol se había dirigido a todos los fieles en Roma, tanto si provenían de la gentilidad como del judaísmo, pero que en ese momento se dirige particularmente a los gentiles conversos, como le incumbe por oficio en cuanto su apóstol y maestro (n. 887). Y hace honor a su ministerio, comenta santo Tomás, en primer lugar mediante su buena conducta (bonis moribus), según 2 Co 6,4, y no por honores mundanos; también por excederse en lo que le correspondía hacer (per supererogationem operum), según 1 Co 9,18; y además, por extender su solicitud a la salvación de todos (ampliando sollicitudinem ad omnium salutem), según 2 Co 11,28. De este modo provocaba un celo bueno y una emulación en los judíos con vistas a su salvación. Podría parecer, advierte el Aquinate, que como Apóstol de los gentiles esto no le incumbía y que inmiscuirse en la tarea de otros no honraba su ministerio. Al contrario, aclara santo Tomás (n. 889): aunque predicar a los gentiles le correspondía por el mandato de evangelizar, tampoco tenía prohibido predicar a los judíos; por eso el interés por la salvación de los judíos honraba su ministerio y era un signo de esperanza, no solo actual sino de largo alcance e incluso en un sentido escatológico ${ }^{33}$.

\section{Palabras "familiares"}

Santo Tomás observa que en el penúltimo capítulo (a partir de Rm 15,14) el Apóstol cambia la temática de la epístola y el tono: en lugar de las advertencias generales de tipo doctrinal y moral con que los había instruido hasta ese momento, les hace ahora unas consideraciones "familiares", en las cuales habla pri-

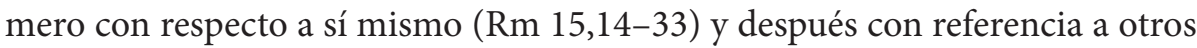
$(\mathrm{Rm} \mathrm{16})^{34}$.

33 Aquí hace santo Tomás una observación de interés sobre la conversión de los judíos en relación con los "gentiles" que son los cristianos en un estado de tibieza: "Gentiles enim sunt fideles qui tepescent, Matth. 24, 12: Quoniam abundavit iniquitas refrigescet charitas multorum. Vel etiam qui totaliter cadent decepti ab Antichristo, Iudaeis conversis in pristinum fervorem restituentur. Et etiam sicut Iudaeis cadentibus, Gentiles post inimicitias sunt reconciliati, ita post conversionem Iudaeorum, imminente iam fine mundi, erit resurrectio generalis, per quam homines ex mortuis ad vitam immortalem redibunt" (n. 890).

34 "Postquam Apostolus generalibus admonitionibus romanos instruxerat, hic incipit eis quaedam familiaria scribere. Et primo quaedam pertenentia ad seipsum; secundo, quae- 
En lo que se refiere al propio Apóstol, comenta santo Tomás, hace tres cosas: primero se excusa por haberles amonestado "con mayor audacia" y les explica los motivos (Rm 15,14-21); a continuación lamenta su tardanza en vi-

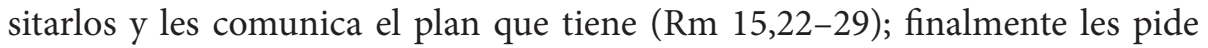
con énfasis (obsecro) oraciones por su persona (Rm 15,30-33). El Aquinate se extiende sobre el primer punto, donde destaca el talante humano de Pablo, su sentido de responsabilidad y sus cualidades pastorales (nn. 1164-1177). Tiene particular interés el modo de comentar los vv. 14 y 15: Pablo no escribe a los Romanos - dice santo Tomás- como quien se cree en condiciones de instruir y corregir a otros, porque está seguro de que ellos mismos tienen toda la preparación y las condiciones para amonestar a quienes lo necesiten, pero advierte que todos fallamos en muchas cosas y necesitamos corregirnos mutuamente (n. 1164). A continuación explica la motivación y el sentido de haberles hablado audacius: porque quizá algunos lo necesiten particularmente, también porque quiere recordarles cosas que tal vez hayan olvidado y, sobre todo, porque es consciente de su propia responsabilidad y autoridad apostólica, para cuyo ejercicio tiene la gracia de Dios (nn. 1166-1167). Esto es solo un ejemplo de cómo el Aquinate busca comprender la mente y las actitudes del Apóstol. El capítulo termina con las palabras: "El Dios de la paz esté con todos vosotros. Amén" (Rm 15,33), cuyo breve comentario dice que cuentan con la oración del Apóstol y que la paz se entiende también como recíproca entre ellos.

En cuanto al capítulo 16, donde las "palabras familiares" del Apóstol conciernen no a él sino a otros, el Aquinate distingue tres planos entre la multitud de nombres, encargos y temas. En primer lugar indica a los fieles en Roma a qué personas han de saludar y de qué modo (vv. 1-16, nn. 1193-1212), pero también les advierte a quienes deben evitar en cuanto suponen un peligro para ellos y les promete que cuentan con el auxilio divino para ello (vv. 17-20, nn. 1213-1220). En segundo lugar dice que les saludan quienes están con él (vv. 21-23, n. 1221) y en tercer lugar lo hace Pablo mismo (v. 24, n. 1222). Este tercer paso concluye en una acción de gracias y doxología, que es propiamente el final de la Carta (vv. 25-27, nn. 1223-1227).

Se puede observar que santo Tomás comenta ampliamente, sin omitir ninguno de los muchos nombres de personas -hombres y mujeres- y menciona también a dos familias (domus) ${ }^{35}$. A veces se extiende más, según el grado de familiaridad de estas personas con el Apóstol o la importancia que tengan en las distintas comunidades de fieles, como es el caso de Febe que recibe una

dam pertenentia ad alios ibi cap. Xvi" (n. 1163).

35 Los datos que aporta el Aquinate sobre las personas proceden algunas veces de la Glosa Petri Lombardi, PL 191, ad loc. 
mención más detallada (nn. 1194-1197). En cambio, cuando comenta sobre quiénes deben evitar (nn. 1214-1218), no aparece ningún nombre -tampoco en el texto paulino- sino que advierte solamente la presencia de algunos judaizantes entre los conversos que confundían a los fieles y creaban divisiones.

En todo el comentario a esta parte, sin que sea necesario entrar en más detalles, resalta la cercanía humana de san Pablo con las personas: el aprecio que les tiene individualmente y en cuanto comunidad de fieles, su solicitud pastoral y su agradecimiento particular en algunos casos. Santo Tomás se hace eco también de las dos despedidas del Apóstol al concluir la Carta: Rm 15,33 ("El Dios de la paz esté con todos vosotros. Amén”, y Rm 16,24 ("Que la gracia de nuestro Señor Jesucristo esté con todos vosotros. Amén”), que recuerda lo que había comentado sobre los dos bienes que Dios nos otorga: la gracia para la vida actual y la paz, que será colmada definitivamente en la vida eterna (n. 70, sobre $\mathrm{Rm} \mathrm{1,7).} \mathrm{Con} \mathrm{ello} \mathrm{da} \mathrm{a} \mathrm{entender} \mathrm{nuevamente} \mathrm{la} \mathrm{actitud} \mathrm{de} \mathrm{benevolencia}$ y solicitud pastoral de san Pablo hacia los fieles que están en Roma.

El comentario a esta parte final de la epístola contiene materia suficiente para un estudio aparte y excedería el marco de este trabajo; aquí nos hemos limitado a averiguar qué significa quaedam familiaria en cuanto al contenido y la forma, porque refleja el interés y aprecio de santo Tomás por la persona de Pablo.

\section{El perfil de san Pablo en los textos seleccionados}

Se ha hecho una selección y descripción de textos que muestran a san Pablo desde dos puntos de vista diferentes, tanto de género literario como de enfoque. El prólogo tiene la forma de accessus ad auctorem ${ }^{36}$, con su propio estilo y método, mientras que las demás referencias sobre el Apóstol pertenecen al comentario del texto paulino y tienen características metodológicas distintas. Nos fijamos primero en el contenido de una y otra parte de los textos para señalar coincidencias y obtener una síntesis de cómo santo Tomás veía a san Pablo.

\section{a) El prólogo}

Vas electionis: Esta imagen bíblica relacionada con la conversión de san Pablo (Hch 9,15) es, como hemos visto, la base sobre la cual el Aquinate construye un perfil completo del Apóstol. Abarca sus cualidades humanas, la excelencia de sus virtudes, el conocimiento profundo de los misterios divinos, su búsqueda

36 Cfr. Th. Domanyi, Der Römerbriefkommentar des Thomas von Aquin, p. 187. 
de identificación con Cristo, así como la generosidad y fidelidad en llevar la doctrina cristiana a todas partes de modo incansable. En cuanto al contenido que abarca la imagen de vas electionis, se puede hablar de una convicción de santo Tomás por la frecuencia con que recurre a ella cuando habla de san Pa$\mathrm{blo}^{37}$. Es el retrato de una persona que ha respondido con total generosidad a la elección de Dios y sus designios a lo largo de su vida y en todos los aspectos. En definitiva, aunque no lo dice, el Aquinate construye de manera más bien indirecta el retrato de un santo y apóstol, donde resalta también el protagonismo de Dios. A la vez se trasluce una actitud de veneración personal ${ }^{38}$.

\section{b) Los demás textos}

El comentario a las referencias personales de san Pablo en la Carta muestra al Apóstol mientras camina en la tierra, en pleno desarrollo de su misión. El comentador se mantiene en un segundo plano, explicando el texto con la profundidad y maestría acostumbradas. En dos momentos, como se ha visto, emplea también la imagen de vas electionis, a propósito de la vocación y misión de san Pablo. Al hilo de esas referencias personales del Apóstol muestra la generosidad incondicional en su respuesta a Dios y el alto grado de sus virtudes: humildad, contemplación, caridad, servicio incansable y progreso espiritual. En el modo de dirigirse a los destinatarios de la Carta ( $\mathrm{Rm} 1,7$ y 8,16), el Aquinate descubre algunos rasgos humanos como el afecto, la estima, la benevolencia y la cercanía también humana que san Pablo siente por ellos, así como la solicitud pastoral, concretada en el deseo apremiante de visitarlos. Muestra también que, como Apóstol de los gentiles, se excede en este ministerio propio de su vocación, pero que a la vez se siente profundamente judío, con un gran amor a su pueblo y el afán de contribuir a su salvación ( $\mathrm{Rm} \mathrm{11,13-16).}$

Es de particular interés el detallado comentario a los últimos dos capítulos (a partir de Rm 15,14), cuyo contenido el Aquinate denomina quaedam fami-

37 Aunque aquí nos centramos en la Carta a los Romanos, la imagen bíblica de Hch 9, 15 como característica de san Pablo aparece también en otros lugares del comentario de santo Tomás al Corpus Paulinum, con los aspectos de elección divina, de la que Pablo es plenamente consciente, y su correspondencia personal: II ad Cor, nn. 4, 358, 473-474; Ad Eph, nn. 144 y 150; Ad Gal, n. 34; I ad Thes, n. 28; I ad Tim, n. 69; II ad Tim, n. 167; Ad Titum, n. 8 .

38 Esta cercanía a san Pablo y la veneración por él se menciona también en las fuentes hagiográficas sobre Tomás de Aquino: J.M. Voste, Sanctus Thomas epistularum, p. 275: "S. Thomas mente et corde interpretatus est Paulum, ad quem «specialem devotionem habuit»"; las palabras últimas son una cita de P. Mandonnet en Fontes vitae S. Thomae Aquinatis, pp. 233-234. 
liaria. Se hace cargo de la importancia de esas relaciones humanas para Pablo y para conocer la vida de los primeros cristianos, de modo que las comenta con la misma exactitud que emplea en la parte anterior de la Carta.

Estos distintos escenarios de la epístola contrastan ciertamente con la imagen que ofrece el prólogo, pero coinciden perfectamente en el contenido. En efecto, la comprensión que san Pablo tiene de sí mismo, sus actitudes básicas, sus planes y sus virtudes no solo concuerdan con la imagen del Vas electionis en el prólogo, sino que le dan vida y crean una cercanía al Apóstol.

\section{Características metodológicas}

Como ya se ha dicho, los textos seleccionados se distinguen por pertenecer a géneros literarios distintos, con unos procedimientos exegéticos también diferentes.

\section{a) En cuanto al género literario}

Los prólogos o introducciones, llamados también accessus, de los comentarios bíblicos medievales tenían distintas formas literarias, entre las que el Aquinate elegía o adaptaba las que le parecían más adecuadas para el libro que iba a comentar; de hecho son diferentes sus prólogos cuando comenta, por ejemplo, libros del Antiguo Testamento, el Evangelio de San Juan o la Carta a los Romanos ${ }^{39}$.

El prólogo a la Carta a los Romanos tiene características especiales. Como ya se ha visto, consta de dos partes: la semblanza de san Pablo como autor humano y la obra que son las Cartas, es decir todo el Corpus Paulinum, incluida la Carta a los Hebreos ${ }^{40}$. Si la primera parte tiene forma de ensayo con su propio hilo argumental y estilo, la segunda parte consiste en un análisis temático de las Cartas, perfectamente estructurado en un orden lógico. Sin embargo no hay un corte entre ambas partes del prólogo, en primer lugar porque el "puente" entre persona y obra es sólido, pues está construido mediante el principio de las cuatro causas ${ }^{41}$. Además se observa una unidad dinámica entre ambas partes del prólogo, porque todo se sitúa en el plan salvador de Dios: la elección del

39 Cfr. Th. Domanyi, Der Römerbriefkommentar des Thomas von Aquin, pp. 187-188.

40 Santo Tomás conocía las dudas sobre la autoría de san Pablo. Lo manifiesta en el prólogo a ese comentario, aunque él mismo opta por la autoría paulina, cfr. Super Epistolam ad Hebraeos lectura, n. 5.

41 Cfr. Th. Domanyi, Der Römerbriefkommentar des Thomas von Aquin, pp. 190-191. 
instrumento por la gracia divina, que es plenamente correspondida, y porque el tema común de las Cartas es también la gracia, que se expone de diversas maneras en ellas.

Es una unidad que el estudioso contemporáneo quizá tenga dificultad en percibir, sobre todo si se deja abrumar por el aparato metodológico de la escolástica como los análisis estructurales de la obra y la divisio textus. A la vista de tales procedimientos de santo Tomás surge a veces la pregunta de si esto no es descontextualizar al autor sagrado. La solución está en "re-pensar", retrocediendo en la historia, los escritos del Aquinate según su propia mente para conocer su modo de leer la Sagrada Escritura y las herramientas científicas que él usó al interpretarla; solo así es posible acceder al núcleo de su pensamiento teológico y descubrir el contenido atemporal. Algunos estudios recientes se hacen eco de esta dificultad y aportan una orientación ${ }^{42}$.

\section{b) Modos de interpretación bíblica}

Los textos escogidos para este trabajo son una mínima parte del comentario de santo Tomás a Romanos, pero constituyen una muestra válida sobre el modo en que lee, explica y trabaja con la Sagrada Escritura en cuanto fuente principal de la teología. Se señalan algunos aspectos que ofrecen esos textos sobre el modo en que trabaja el Aquinate con y sobre la Sagrada Escritura.

En primer lugar destaca la Sagrada Escritura misma como medio de profundización y explicación de un texto bíblico; esas citas no son nunca un adorno literario ni meras referencias paralelas o datos de erudición, sino que tienen una función teológica al servicio de la verdad ${ }^{43}$. Reflejan al mismo tiempo la familiaridad de santo Tomás con toda la Biblia, que presupone no solo un aprendizaje exigente sino también la reflexión y meditación del texto sagrado.

Tiene especial interés la función que concede el Aquinate al lenguaje metafórico de la Biblia, como se puede notar en el Prólogo, sobre todo en el uso de la expresión Vas electionis, que hace vislumbrar la amplitud y profundidad del misterio divino a la vez que es concreta en la aplicación. Como santo Tomás incluye el hablar metafórico en el sentido literal de la Sagrada Escritura, según la intención del autor principal, se sirve con frecuencia de metáforas bíblicas

42 Vid. M. Estler, «Rigans montes» (Ps 104,13), pp. 312-314. Compara las dos lecciones inaugurales de santo Tomás Rigans montes e Hic est liber con su prólogo a la Carta a los Romanos, a la vez que se hace eco de la dificultad del lector contemporáneo ante la teología aquiniana.

43 Cfr. L. Elders, Tomás de Aquino, comentador, p. 962. Un estudio reciente y detallado sobre este tema: P. Roszak, The Place and Function. 
para referirse a manifestaciones del misterio de Dios sin limitarse a explicaciones conceptuales. Al mismo tiempo, las metáforas aportan belleza al lenguaje, de modo que agradan y mueven ${ }^{44}$. Alguna vez, como se ha podido observar, se sirve de la alegoría o de la tipología para ilustrar algún aspecto, concretamente en el prólogo.

Los textos descritos muestran también el interés de santo Tomás por la verificación histórica con los medios a su alcance, como consecuencia de su visión histórica de la salvación y del hombre ${ }^{45}$. Este interés por la exactitud científica se muestra también en el análisis lingüístico, como hemos podido observar, con los medios limitados en su época. Tampoco faltan los recursos típicamente escolásticos, como el tratamiento dialéctico de un texto, cuando se trata de poner de acuerdo dos datos bíblicos aparentemente contradictorios, como se ha podido ver en uno de los textos del comentario ${ }^{46}$. Se percibe una jerarquía de instrumentos de exégesis bajo la primacía de la propia Sagrada Escritura. Aunque cada uno de estos medios tiene su lugar y su utilidad concreta, todo se ve en una unidad al servicio del contenido, no solo teórico sino que tiene también una vertiente práctica. En efecto, el lector del comentario encuentra constantemente sugerencias para la propia conducta, ya sea por el modo de comentar la doctrina o por la manera de presentar la vida y actividad de san Pablo, sin que adopte un tono moralizante.

\section{A modo de conclusión}

Se trataba de averiguar la relación de santo Tomás con san Pablo a través de los textos seleccionados. Una pregunta era por qué utilizó una metáfora para caracterizar a san Pablo y concretamente ésta. No sabemos exactamente por qué. A la vista del contenido que el Aquinate ha logrado desplegar a partir de la frase Vas electionis est mihi iste (Hch 9,15) cabe pensar en la profundidad con

44 Cfr. Th. Domanyi, Der Römerbriefkommentar des Thomas von Aquin, pp. 166-169. Sobre este tema en santo Tomás puede verse también una monografía anterior: M. Arias Reyero, Thomas von Aquin als Exeget, pp. 167-206; Th. Prügl, Thomas Aquinas as Interpreter, pp. 391-401; y un reciente estudio específico: G. Dahan, Thomas Aquinas: Exegesis and Hermeneutics.

45 Este aspecto de la teología de santo Tomás, aunque se ha empezado a estudiar, es todavía un desiderátum, como muestra el artículo de Jean-Pierre Torrell: Saint Thomas et l'histoire.

46 A propósito de la expresión "siervo de Jesucristo" (Rm 1,1) santo Tomás argumenta con otros textos bíblicos que esto no contradice el hecho de ser amigo del Señor (nn. 20-21). Cfr. Th. Domanyi, Der Römerbriefkommentar des Thomas von Aquin, p. 102. 
que leía la Sagrada Escritura, tanto desde el punto de vista científico como contemplativo. La metáfora bíblica no se limita a la semblanza que traza el prólogo, sino que es capaz de abarcar la persona, la vida y la obra del Apóstol a la luz del designio de Dios.

El prólogo, como se ha sugerido, muestra el retrato de un santo, no como en la hagiografía habitual, sino con un estilo más bien indirecto. Después, al profundizar en la autocomprensión del Apóstol y en las relaciones que mantiene con las personas se manifiestan de modo concreto las virtudes de un santo.

En cuanto a la relación personal del Aquinate con san Pablo, se puede afirmar que los textos escogidos muestran, de diferentes maneras, una sintonía con el Apóstol. En el modo de comentar se descubre una comprensión de fondo de la doctrina de la Carta.

En este trabajo se han tenido en consideración solamente algunos textos del comentario a una de las Cartas paulinas. Por lo tanto la conclusión tiene un carácter limitado, aunque cierto.

\section{Bibliografía}

Arias Reyero, M., Thomas von Aquin als Exeget. Die Prinzipien seiner Schriftdeutung und seine Lehre von den Schriftsinnen, Johannes Verlag, Einsiedeln 1971.

Berceville, G., Avant-propos, in: Thomas d'Aquin, Commentaire de l'Épitre aux Romains, Cerf, Paris 1999, pp. 7-17.

Dahan, G., Thomas Aquinas: Exegesis and Hermeneutics, en: Vijgen, J., Roszak, P., (eds.), Reading Sacred Scripture with Thomas Aquinas. Hermeneutical Tools, Theological Questions and New Perspectives, Brepols (Textes et Etudes du Moyen Âge, FIDEM-TEMA, 80), Turnhout 2015, pp. 45-70.

Domanyi, Th., Der Römerbriefkommentar des Thomas von Aquin. Ein Beitrag zur Untersuchung seiner Auslegungsmethoden, Peter Lang, Bern-Frankfurt am Main-Las Vegas 1979.

Elders, L.J., La actualidad de la Carta de San Pablo a los Romanos según el comentario de Santo Tomás, en: idem, Conversaciones teológicas con santo Tomás de Aquino, Ediciones del Verbo Encarnado, San Rafael-Mendoza 2008, pp. 97-115

Elders, L.J., Tomás de Aquino, comentador de San Pablo, Scripta theologica 38/3 (2006), pp. 941-963.

Estler, M., «Rigans montes» (Ps 104,13). Die Antrittsvorlesung des Thomas von Aquin in Paris 1256, Verlag Katholisches Bibelwerk (Stuttgarter Biblische Beiträge, 73), Stuttgart 2015.

Prügl, Th., Thomas Aquinas as Interpreter of Scripture, en: Van Nieuwenhove, J. Wawrykow, J., The Theology of Thomas Aquinas, University of Notre Dame Press, Notre Dame, Indiana 2005, pp. 386-415. 
Roszak, P., The Place and Function of Biblical Citations in Thomas Aquinas's Exegesis, en: Vijgen, J., Roszak, P. (eds.), Reading Sacred Scripture with Thomas Aquinas. Hermeneutical Tools, Theological Questions and New Perspectives, Brepols (Textes et Etudes du Moyen Âge, FIDEM-TEMA, 80), Turnhout 2015, pp. 115-139.

Taylor Coolman, H., Romans 9-11. Rereading Aquinas on the Jews, en: Levering, M., Dauphinais, M., Reading Romans with Thomas Aquinas, The Catholic University of America Press, Washington, D.C. 2012, pp. 101-112.

Torrell, J.-P., Nouvelles recherches thomasiennes, Librairie Philosophique J. Vrin (Bibliothèque Thomiste, 61), Paris 2008.

Torrell, J.-P., Amico della verità: vita e opere di Tommaso d'Aquino, Edizioni Studio Domenicano, Bologna 2006.

Torrell, J.-P., Saint Thomas et l'histoire. État de la question et pistes de recherches, Revue Thomiste, 105/3 (2005), pp. 355-409.

Vijgen, J., Roszak, P. (eds.), Reading Sacred Scripture with Thomas Aquinas. Hermeneutical Tools, Theological Questions and New Perspectives, Textes et Etudes du Moyen Âge, Brepols (FIDEM - TEMA, 80), Turnhout 2015.

Voste, J.M., Sanctus Thomas epistularum s. Pauli interpres, Angelicum 19 (1942), pp. 257-276.

Weisheipl, J.A., Tomás de Aquino. Vida, obras y doctrina. Edición española al cuidado de Josep-Ignasi Saranyana, Eunsa, Pamplona 1994. 